Original article

\title{
Crossbreeding effect of double-muscled cattle on in vitro embryo development and quality
}

\author{
Gretania Residiwati $^{\mathrm{a}, *}$, Habib S.A. Tuska ${ }^{\mathrm{a}}$, Nima-Azari Dolatabad ${ }^{\mathrm{a}}$, Shehu Sidi ${ }^{\mathrm{b}}$, \\ Petra Van Damme ${ }^{\mathrm{a}}$, Krishna C. Pavani ${ }^{\mathrm{a}}$, Osvaldo Bogado Pascottini ${ }^{\mathrm{a}, \mathrm{c}}$, Geert Opsomer ${ }^{\mathrm{a}}$, \\ Ann Van Soom ${ }^{\mathrm{a}}$ \\ ${ }^{a}$ Department of Reproduction, Obstetrics and Herd Health, Faculty of Veterinary Medicine, Ghent University, Merelbeke, Belgium \\ ${ }^{\mathrm{b}}$ Department of Theriogenology and Animal Production, Usmanu Danfodiyo University, Sokoto, Nigeria \\ ${ }^{\mathrm{c}}$ Department of Veterinary Sciences, Gamete Research Center, Veterinary Physiology and Biochemistry, University of Antwerp, Wilrijk, Belgium
}

\section{A R T I C L E I N F O}

\section{Keywords:}

Belgian Blue

fertility

semen

oocyte

\begin{abstract}
A B S T R A C T
Nowadays, several developing countries have started to breed double-muscled cattle to their autochthonous cattle to improve meat production. However, the developmental competence of the resultant crossbreeding embryos is unknown. The objective of this study was to evaluate the effect of crossbreeding double-muscled (Belgian Blue; BB) semen with beef (Limousin; LIM) and dairy (Holstein-Friesian; HF) derived oocytes on embryo development and quality, using purebred $\mathrm{BB}$ as a control (BB oocytes fertilized by BB sperm). A single ejaculate of a BB bull was evaluated by Computer Assisted Sperm Analysis before using for in vitro fertilization. Ovaries from each breed were collected at the local slaughterhouse $(n=1,720$ oocytes). All statistical analyses were performed using R-core $(P<0.05)$. Embryo quality was evaluated via differential-apoptotic staining of day 8 blastocysts. Cleavage $(48 \mathrm{~h}$ post insemination) and day 8 blastocyst rates were greater $(P<0.05)$ for LIM $(82.9 \pm 6$ and $27 \pm 4.3 \%$, respectively) than for $\mathrm{BB}(69.8 \pm 8.5$ and $19.6 \pm 3.1 \%$, respectively) and $\mathrm{HF}$ (45.1 \pm 10 and $12.3 \pm 2.2 \%$, respectively). Holstein-Friesian presented lower cleavage and day 8 blastocyst rates than $\mathrm{BB}(P<0.05)$. Limousin blastocysts presented a higher number $(P<0.05)$ of inner cell mass cells (ICM; $68 \pm 7.8)$ than HF $(40.4 \pm 8.2)$. In conclusion, crossbreeding double-muscled cattle by in vitro fertilization with LIM oocytes yielded better embryo compared with the purebred combination, while the combination with HF oocytes produced the lowest rate of blastocysts.
\end{abstract}

\section{Introduction}

Double-muscled cattle might be a valid alternative for crossbreeding autochthonous cattle in developing countries to improve meat production. Double-muscling in cattle is a genetic condition that occurs in several breeds such as Belgian Blue (BB), Piedmontese, and Marchigiana [1]. It has been reported that double muscling in BB cattle significantly increases carcass yield and meat tenderness [[2]], characteristics that are desirable in the meat industry. Some research groups uncovered that double-muscling is caused by mutations in the myostatin gene [3]. Among other functions, myostatin appears to play a role in the regulation of protein synthesis and glucose metabolism [4]. Although this condition results in improved meat quality and quantity, it also comes along with problems associated with reduced reproductive performance [5]. The sub-development of the hip bone (relative to the size of the animal) [6], the extended gestation period [7], and the higher birth weight of the offspring is associated higher risk of dystocia and perinatal calf mortality in double-muscled cows than non-double-muscled cows [8].

Fertility is a multifactorial trait that could be affected by many extrinsic factors such as estrus detection, timing of artificial insemination (AI) relative to ovulation, AI technique, reproductive pathologies, among others [9]. The use of an in vitro approach could help us to eliminate these extrinsic confounders to focus on the inputs of the oocyte and sperm on early embryonic development. A previous study reported more competent oocytes in double-muscled BB than in Holstein-Friesian (HF) dairy cows [10]. In contrast, semen characteristics are known to be markedly lower in BB than HF or crossbreed bulls [11]. The latter might be associated with smaller reproductive organ sizes and a not well defined scrotal neck in BB bulls in comparison to nondouble muscled cattle breeds [3]. However, no study has been performed to associate the potential contribution of $\mathrm{BB}$ semen crossbred

\footnotetext{
* Corresponding author.

E-mail address: habibresibismillah@gmail.com (G. Residiwati).
} 
with oocytes derived from other breeds on their subsequent embryo development and quality.

We hypothesized that crossbreeding double-muscled semen with oocytes derived from distinct beef and dairy breeds, will affect their subsequent in vitro embryo assessments. Thus, the objective of this study was to evaluate the effects of in vitro crossbreeding of doublemuscled (BB) sperm with beef (Limousin; LIM), dairy (HF) as well as with double-muscled purebred (BB) derived oocytes on blastocyst development and quality. The evaluation of blastocyst development included cleavage rate (CR), and day 7 and 8 embryonic rates. For blastocyst quality, we evaluated the total cell number (TCN), trophectoderm cells (TE), inner cell mass (ICM), ICM/TCN ratio, total apoptotic cells (AC), and AC/TCN ratio via differential/apoptotic staining of day 8 blastocysts. This could be considered as a first step to study the potential contribution of BB bulls in crossbreeding systems to maintain the benefit of meat production without an undesirable toll in fertility.

\section{Materials and methods}

\subsection{Sperm collection, cryopreservation, and post-thawing quality} assessment

A single ejaculate from a BB bull located in the breeding center of AWE in Ciney (Belgium; $50^{\circ} 29 \mathrm{~N}, 5^{\circ} 11 \mathrm{E}$ ) was used for all the experiments. The semen of the BB bull used for this experiment is commercially available. Thus, its fertility performance is continuously monitored via multiple reproductive parameters (e.g., non-return rate after AI) at the field level. The ejaculate was collected in spring 2016 using an artificial vagina after which it was cryopreserved via the standard procedure. Briefly, the semen sample was extended via OptydilTM (Minitüb GmbH, Germany) and cooled ( $4{ }^{\circ} \mathrm{C}$ for $4 \mathrm{~h}$ ). Then, it was loaded into $0.25 \mathrm{~mL}$ straws (IMV Technologies) at $4{ }^{\circ} \mathrm{C}$. The freezing was carried out via a programmable freezing system (IMV, Technologies-Digitcool, L'Aigle, France). After that, the straws were cooled to $-10{ }^{\circ} \mathrm{C}$ at $-5{ }^{\circ} \mathrm{C} / \mathrm{min}$, from $-10{ }^{\circ} \mathrm{C}$ to $-140{ }^{\circ} \mathrm{C}$ at $-40{ }^{\circ} \mathrm{C} / \mathrm{min}$ and were subsequently plunged into liquid nitrogen.

A frozen sperm sample was thawed at $37{ }^{\circ} \mathrm{C}$ for 30 seconds. After thawing, the sample was evaluated for motion kinetics using a computer assisted sperm analyzer (CASA; ISAS ${ }^{\circledR}$ v1 CASA system, Proiser, Spain) with three replicates. Briefly, a droplet $(3 \mu \mathrm{L})$ of the sample was placed in a pre-warmed Leja chamber $\left(37^{\circ} \mathrm{C}\right.$; Leja counting chambers, depth $20 \mathrm{~mm}$; Microptics ${ }^{\circledR}$, Barcelona, Spain) and automatically assessed for motion kinetics using a 10x negative phase contrast microscope objective (connected to the CASA system). The settings of the CASA software are presented in Supplemental Table S1 and motion kinetic parameters of the frozen-thawed semen sample are presented in Supplemental Figure S2.

\subsection{Oocyte collection and embryo production}

Ovaries from each breed (BB as for double-muscled, LIM as for beef, and $\mathrm{HF}$ as for dairy) were collected at the local slaughterhouse and transferred to the laboratory facilities allocated in independent and well identified bags. Belgian Blue derived oocytes fertilized with BB sperm (purebred) was used as control for embryo development and quality. Experiments were run in three replicates (three different days using different batches of media), and for each replicate we included the following combinations: BB semen and BB oocytes vs. BB semen and HF oocytes vs. BB semen and LIM oocytes. In all the cases, frozen-thawed semen samples from the same BB bull were used (as described above). Basic Eagle's Medium amino acids, minimal essential medium non-essential amino acids (100 x), TCM-199-medium, kanamycin, and gentamycin were purchased from Life Technologies Europe (Ghent, Belgium). All other components were obtained from Sigma (Schnelldorf, Germany) unless otherwise stated. All the media were filter-sterilized using a $0.22 \mathrm{~mm}$ filter (Pall Corporation, Ann Arbor, MI, USA) before use.

The production of in vitro bovine blastocysts was done as described by Wydooghe et al. (2014) [12]. Briefly, using an 18-gauge needle attached to a $10 \mathrm{ml}$ syringe, the cumulus-oocytes complexes (COCs) were recovered from follicles with a diameter of 2-8 $\mathrm{mm}$. Oocytes with homogeneous dark cytoplasm and compact cumulus cells were selected and matured in groups of 60 in $500 \mu \mathrm{l}$ of bicarbonate-buffered TCM199 medium supplemented with $50 \mathrm{mg} / \mathrm{ml}$ gentamycin and $20 \mathrm{ng} / \mathrm{ml}$ of epidermal growth factor. Oocytes were matured for $22 \mathrm{~h}$ at $38.5{ }^{\circ} \mathrm{C}$ in $5 \% \mathrm{CO}_{2}$ in humidified air. Frozen-thawed BB sperm (same bull and batch) was used for fertilization. The sperm was passed through a discontinuous Percoll ${ }^{\circledast}$ gradient (45:90\% (v:v)) and adjusted to a final concentration of $1 \times 10^{6}$ cells $/ \mathrm{ml}$ in IVF TALP medium.

The matured COCs were washed in $500 \mathrm{ml}$ IVF-TALP and co-incubated with sperm for $21 \mathrm{~h}$ at $38.5{ }^{\circ} \mathrm{C}$ in $5 \% \mathrm{CO}_{2}$ in humidified air. After fertilization, presumptive zygotes were first vortexed to remove the excess of the sperm and cumulus cells, and then cultured in groups of 25 in $50 \mu$ droplets of SOF medium at $38.5{ }^{\circ} \mathrm{C}$ in $5 \% \mathrm{CO}_{2}, 5 \% \mathrm{O}_{2}$, and $90 \% \mathrm{~N}_{2}$. Embryo development was evaluated at $48 \mathrm{~h}$ post-insemination (cleavage), and at day 7 and day 8 .

\subsection{Differential staining of blastocysts}

In vitro-produced day-8 blastocysts were fixed in 4\% PFA for $20 \mathrm{~min}$ at RT and stored at $4{ }^{\circ} \mathrm{C}$ until use. Differential staining was performed as described by Wydooghe et al. (2011) [13]. Blastocysts were permeabilized with $0.5 \%$ Triton X-100 $+0.05 \%$ Tween for $1 \mathrm{~h}$ at RT. Then, DNA of the blastomeres was denatured by exposure to $2 \mathrm{~N} \mathrm{HCl}$ (1.09063.1000, HC98019763, Tritipur ${ }^{\circledR}$, Germany) for 20 min followed by $100 \mathrm{mM}$ Tris- $\mathrm{HCl}(\mathrm{pH} 8.5)$ for $10 \mathrm{~min}$ at RT. Blocking solution consisting of $10 \%$ goat serum and $0.5 \%$ BSA prepared in phosphate buffer saline (PBS; 0000333482 Gibco $^{\circledR}$, UK) was added and the embryos were incubated at $4{ }^{\circ} \mathrm{C}$ overnight. The embryos were washed and incubated in the ready-to-use primary CDX2 antibody (Biogenex, San Ramon, USA) at $4{ }^{\circ} \mathrm{C}$ overnight. Embryos were washed and incubated overnight at $4{ }^{\circ} \mathrm{C}$ in rabbit active caspase- 3 antibody $(0.768 \mu \mathrm{g} / \mathrm{ml}$ in blocking solution, Cell Signaling Technology, Leiden, the Netherlands). After another wash step, test embryos and negative controls (not exposed to CDX2 and Caspase- 3 antibodies) were transferred to goat antimouse Texas Red secondary antibody $(20 \mu \mathrm{g} / \mathrm{ml}$ in blocking solution, Molecular Probes, Merelbeke, Belgium) for $1 \mathrm{~h}$ at RT and to goat antirabbit FITC antibody ( $10 \mu \mathrm{g} / \mathrm{ml}$ in blocking solution, Molecular Probes) for $1 \mathrm{~h}$ at RT. Next, blastocysts were rinsed three times in PBS, counterstained with Hoechst 33,342 $(50 \mu \mathrm{g} / \mathrm{ml}$ in PBS/BSA, Molecular Probes) for $20 \mathrm{~min}$ at RT, and mounted with DABCO mounting medium. This differential staining allowed the assessment of the number of TE cells, inner cell mass number (ICM), total cells number (TCN; TE + ICM), ICM/TCN ratio and total number of apoptotic cells (AC) as well as apoptotic cells ratio (ACR; AC/ TCN). These assessments were done by fluorescence microscopy (Leica DM 5500 B) using a triple bandpass filter, evaluated by an experienced observer.

\subsection{Statistical analyses}

All statistical analyses were performed using R-core (version 3.6.1; $\mathrm{R}$ Core Team, Vienna, Austria). The zygote/embryo was considered as the unit of interest. Generalized mixed effects models were used to test the effect of breed (BB vs. LIM vs. HF) on developmental (cleavage and blastocyst rates) and differential staining parameters (TCN, TE, ICM, ICM/TCN, AC, and AC/TCN). Differential staining parameters were analyzed by Shapiro-Wilk's test and when not normally distributed $(P<0.05)$, were $\log _{10}$ transformed. For all the models the replicate was set as a random effect. Results are expressed as least squares means and standard errors. The differences between treatment groups were assessed using Tukey's post hoc test. The significance and tendency levels 


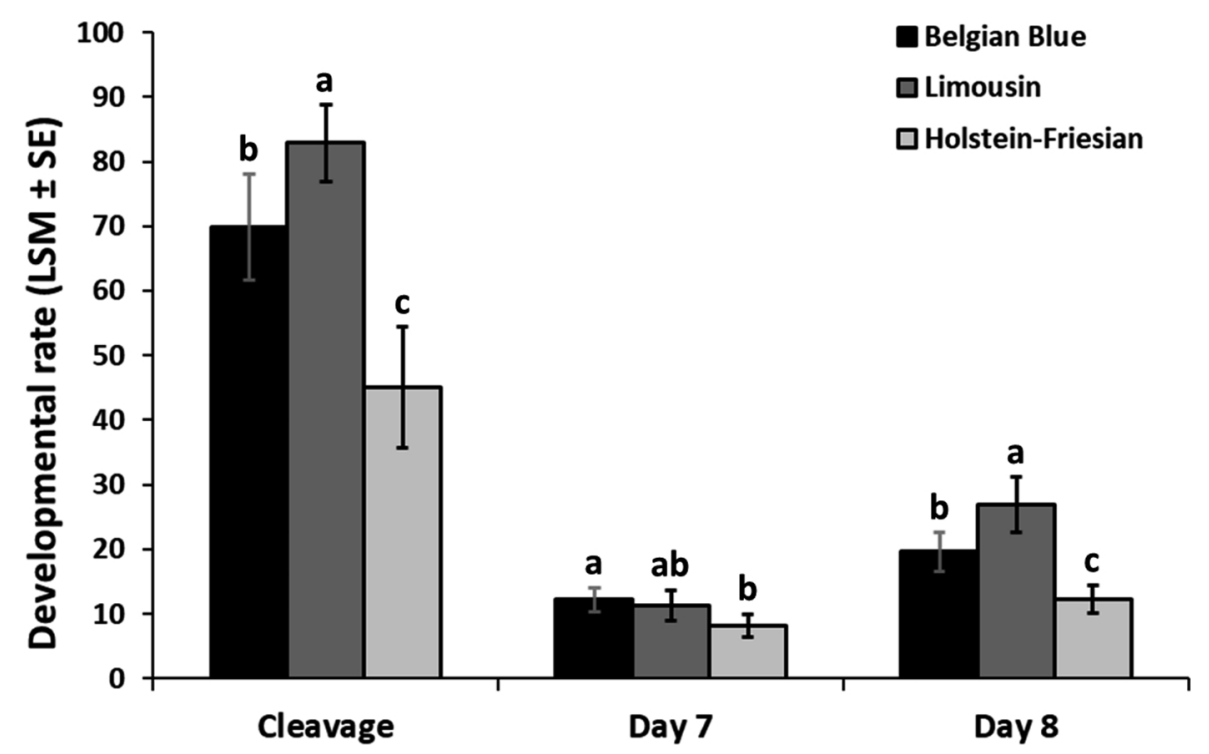

Fig. 1. Cleavage, day 7, and day 8 blastocyst rates expressed as percentage from presumed zygotes. Cumulus oocyte complexes ( $\mathrm{n}=1,720$ ) of doublemuscled (Belgian Blue; BB), beef (Limousin; LIM), and dairy breed (Holstein-Friesian; HF) were fertilized with semen from a single double-muscled (BB) bull. In vitro embryos were standardly produced in groups and cultured in serum-free medium in three replicates. Different superscripts (a, b, and c) represents statistical differences $(P<0.05)$ among groups. Results are expressed as least square means \pm standard error $(\mathrm{LSM} \pm \mathrm{SE})$. were set at $P<0.05$ and $P<0.1$, respectively.

\section{Results}

A total of 1,720 oocytes ( 644 for BB, 274 for LIM, and 802 for HF) in three replicates were used for this study. Cleavage and day 8 blastocyst rates were greater $(P<0.05)$ for LIM $(82.9 \pm 6$ and $27 \pm 4.3 \%$, respectively) than for BB $(69.8 \pm 8.5$ and $19.6 \pm 3.1 \%$, respectively) and HF (45.1 \pm 10 and $12.3 \pm 2.2 \%$, respectively) derived oocytes (Fig. 1). Holstein-Friesian presented lower cleavage and day 8 blastocyst rates than BB derived oocytes $(P<0.05$; Fig. 1$)$. Belgian Blue presented a greater $(P<0.05)$ day 7 blastocyst rate $(12.2 \pm 1.8 \%)$ than $\mathrm{HF}$ $(8.2 \pm 1.8 \%)$ but the day 7 blastocyst rate in LIM $(11.3 \pm 2.3 \%)$ was not different than for BB or HF oocytes $(P<0.05$; Fig. 1$)$. Blastocysts of LIM derived oocytes possessed higher cell numbers in $(P<0.05)$ ICM and ICM/TCN (68 \pm 7.8 and $65.2 \pm 4.3$, respectively) than HF (40.4 \pm 8.2 and $45.9 \pm 4.7$, respectively; Fig. 2 ). No other difference in differential nor apoptotic staining parameter was found among breeds $(P<0.05$; Figs. 2 and 3$)$.

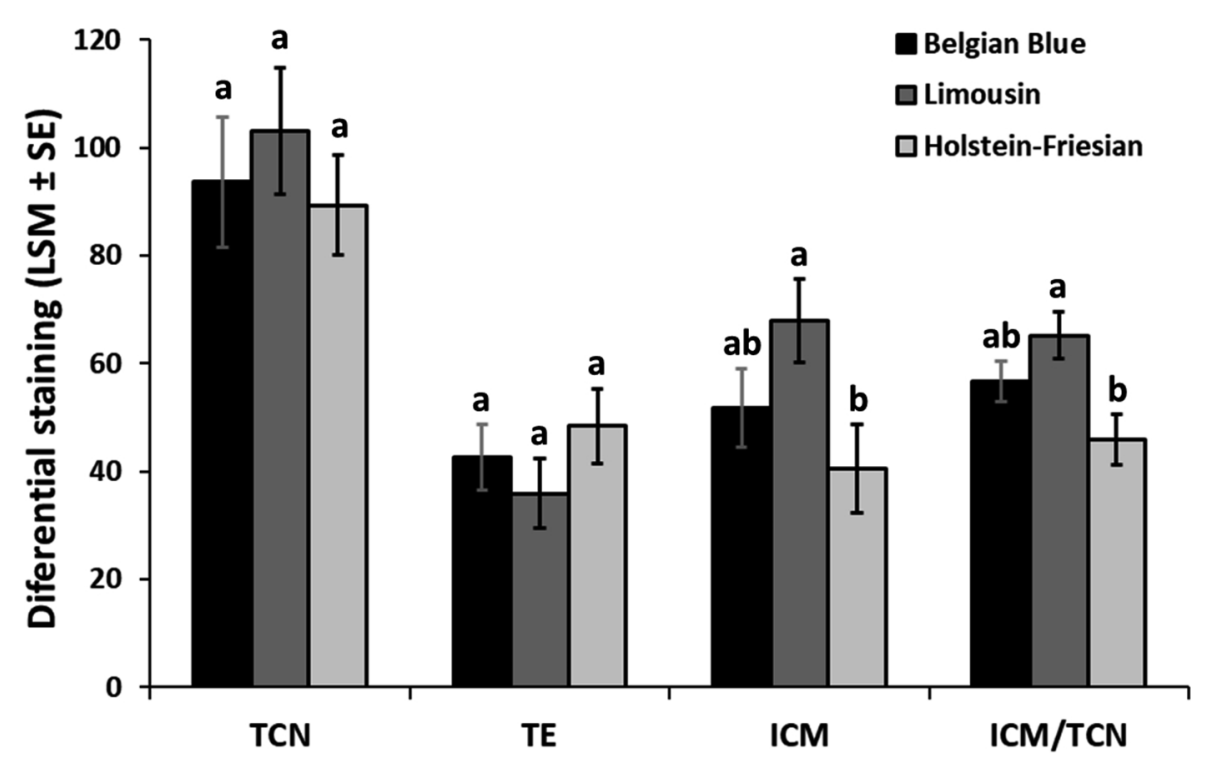

\section{Discussion}

We investigated the effects of crossbreeding double-muscled (BB) semen with LIM (beef), and HF (dairy) derived oocytes on further in vitro embryo development and quality, using the development and quality of purebred derived embryos (semen and oocytes from BB cattle) as a control. Our results show greater developmental capacity in LIM derived oocytes compared to BB and HF. Furthermore, development was significantly higher in BB than in HF. Limousin blastocysts possessed more cells in the ICM than HF. Crossbreeding double-muscled cattle by in vitro fertilization with LIM oocytes yields better embryo development compared with the purebred combination, while the combination with HF oocytes produced the lowest rate of blastocysts. This finding suggests that cross-breeding BB semen with oocytes from other beef breeds may have positive effects on fertility. The crossbreeding effect of $\mathrm{BB}$ semen with dairy cows remains inconclusive since culled HF cows are often culled for infertility or health reasons.

This experiment consisted of a preliminary study to mimic what might be happen concerning aspects of potential fertility in a BB crossbreeding program in Indonesia. We are aware of the multiple limitations of the model. However, results suggest that at least for in vitro settings, crossbreeding BB bulls with other breeds (especially beef)
Fig. 2. Total cell number (TCN), trophectoderm cells (TE), inner cell mass (ICM) and ICM/TCN of day 8 blastocyst differentially stained $(n=63)$. Cumulus oocyte of double-muscled (BB), beef (LIM), and dairy (HF) were fertilized with semen from a single doublemuscled (BB) bull. In vitro embryos were standardly produced in groups and cultured in serum-free medium in three replicates. Different superscripts (a, $\mathrm{b}$, and $\mathrm{c})$ represents statistical differences $(P<0.05)$ among groups. Results are expressed as least square means \pm standard error $(\mathrm{LSM} \pm \mathrm{SE})$. 


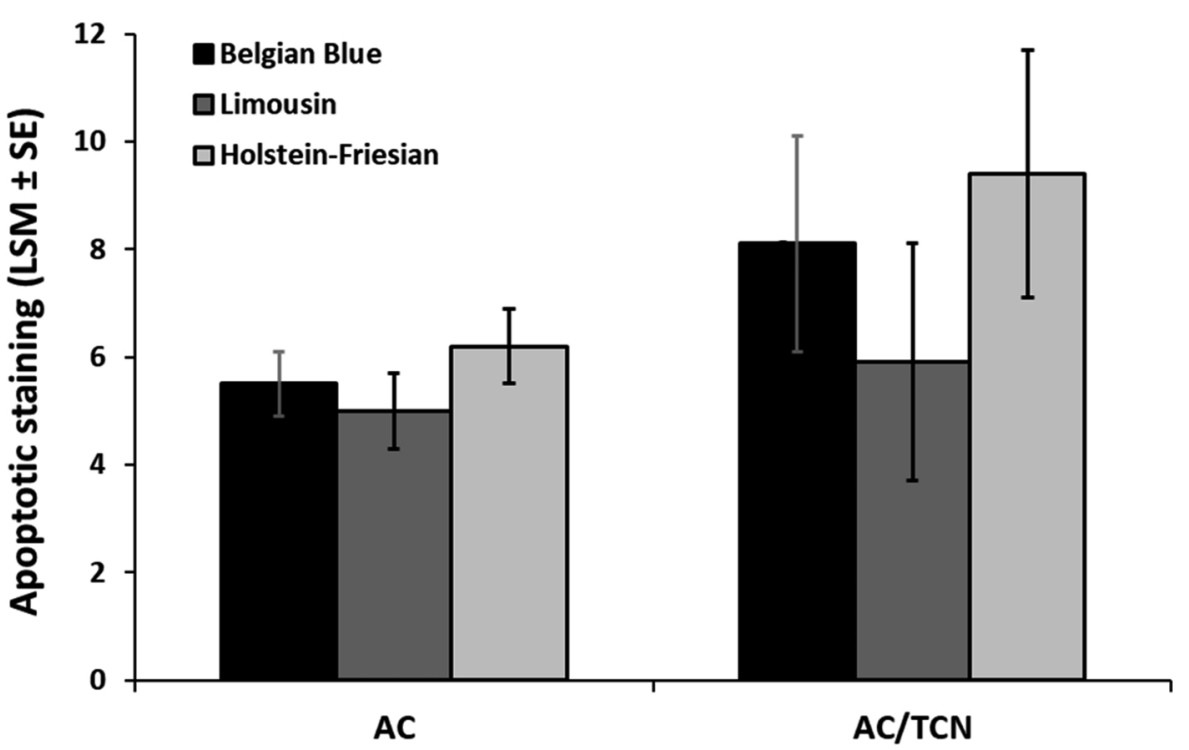

Fig. 3. Total apoptotic cells (AC) and AC/Total cell number (TCN) of day 8 blastocysts subjected to an apoptotic staining $(n=63)$. In vitro matured oocytes of double-muscled (BB), beef (LIM), and dairy (HF) were fertilized with semen from a single double-muscled (BB) bull. In vitro embryos were standardly produced in groups and cultured in serum-free medium in three replicates. No significant differences $(P<0.05)$ were found among groups. Results are expressed as least square means \pm standard error $(\mathrm{LSM} \pm \mathrm{SE})$. will not result in reduced embryonic development. In aspects of in vitro production and fertility, this is one of the first studies reporting the crossbreeding effect of BB with other beef cattle.

Heterosis advantages associated with beef quantity and quality is expected while crossbreeding gametes of double-muscled cattle with other beef cattle. However, this might be accompanied by undesirable, negative effects associated with fertility. Heterosis or hybrid vigour is defined as increased vigor of growth, survival, and fertility of hybrids between two breeds, especially in the first generation. Heterosis is well established in beef cattle, and systems of production that exploit both maternal and individual heterosis may increase production levels by $30 \%$ [14]. Here, we found that the crossbreeding of BB with LIM gametes presented higher blastocyst development than the $\mathrm{BB}$ purebred embryos. This indicates that a crossbreeding program of $\mathrm{BB}$ with other beef (non-double muscled) breeds may not result in lower conception rates. On the other hand, it could be an excellent solution to improve beef quality and fertility simultaneously. Interestingly, LIM oocytes yield embryos with greater ICM numbers compared with the HF crossbreed. In this regard, a recent study showed that ICM number is the best indicator of the blastocysts' ability to implant [15]. Still, results should be interpreted with caution since there is still a large gap between embryo implantation and the delivery of a healthy calf.

In most European countries, the culling of dairy cows represents 10 to $15 \%$ of the total number of cattle slaughtered to fulfill the meat demand [16]. The most common reasons for culling dairy cows are associated with reproductive failure (primary reason), mastitis, udder problems, low milk production, and old age [17]. Oppositely, BB cows are mainly culled to fulfill the meat demand and they are mostly young at culling. In addition, beef cows are not bred for high milk production. Hence, since beef cows lack most of the husbandry and milk production related stressors, they should have better fertility. Milk production in dairy cows is associated with an altered metabolic profile that is characterized by a reduced concentration of circulating insulin growth factor-1, hypoglycemia, and increased concentrations of non-esterified fatty acids and $\beta$-hydroxybutyrate, and haptoglobin. This altered metabolic profile influences the follicular environment, which reverberates on the growing and maturing of the oocyte [18]. Additionally, the altered metabolic profile in dairy cows affects the oocyte developmental capacity and granulosa cell function in vitro [19]. These conditions might then yield oocytes of lower quality impacting on their inferior blastocyst quality as we found in this study.

It is important to mention that we used ovaries derived from the slaughterhouse. Therefore, we do not know the background of the oocytes at the individual cow level. As a consequence, results of this study should be carefully interpreted. Still, all oocytes were processed in the same way for the in vitro production process, and in each replicate, we used oocytes derived from BB, LIM, and HF ovaries. These results should be considered as a first step to study the cross-breeding effect of BB semen with oocytes from other breeds. More studies should be done at the molecular and genetic levels to establish definitive conclusions.

\section{Conclusion}

We used BB semen to fertilize LIM and HF oocytes to study the potential crossbreeding effect on in vitro embryo development and quality. Our results show that blastocyst development is greater in LIM than HF crossbreed or even the BB purebred. Interestingly, LIM presented a higher ICM number than the HF crossbred. This finding might be due to the fact that HF are often culled due to health or infertility reasons. This experiment consisted of a preliminary study to mimic what may happen in aspects of potential fertility in a BB breeding program. Hence, more studies need to be conducted to draw definitive conclusions.

\section{Declaration of Competing Interest}

None.

\section{Acknowledgments}

This research was funded by LPDP (Indonesia Endowment Fund for Education) with number 201707220411226. Thanks to for Euro Meat Group, Belgium, who provided the oocyte samples from different breeds, and Association Wallonne De L'Élevage, Belgium, who provided the sperm samples. Osvaldo Bogado Pascottini was granted by Fonds voor Wetenschappelijk Onderzoek-Vlaanderen (FWO, Research Foundation, Flanders) under project number 12Y5220N.

\section{Appendix A. Supplementary data}

Supplementary material related to this article can be found, in the online version, at doi:https://doi.org/10.1016/j.repbio.2020.07.007.

\section{References}

[1] Aiello D, Patel K, Lasagna E. The myostatin gene: an overview of mechanisms of action and its relevance to livestock animals. Anim Genet 2018;49(6):505-19. https://doi.org/10.1111/age.12696. 
[2] Purchas RW, Morris ST, Grant DA. A comparison of characteristics of the carcasses from Friesian, Piedmontese $\times$ Friesian, and Belgian Blue $\times$ Friesian bulls. New Zeal J Agric Res 1992;35:401-9. https://doi.org/10.1080/00288233.1992.10421348.

[3] Fiems LO. Double muscling in cattle: genes, husbandry, carcasses and meat. Animals 2012;2(3):472-506. https://doi.org/10.3390/ani2030472.

[4] McPherron AC. Metabolic functions of myostatin and GDF11. Immunol Endocr Metab Agents Med Chem 2010;10(4):217-31. https://doi.org/10.2174/ 187152210793663810.

[5] McPherron AC, Lee S-J. Double muscling in cattle due to mutations in the myostatin gene. Proc Natl Acad Sci 1997;94(23):12457-61. https://doi.org/10.1073/pnas.94. 23.12457.

[6] Vissac B, Ménissier F, Perreau B, Manis Y, Marchand H. Étude du caractère culard. VII. - Croissance et musculature des femelles, déséquilibre morphologique au vêlage. Genet Sel Evol 1973;5:23. https://doi.org/10.1186/1297-9686-5-1-23.

[7] Wiener P, Smith JA, Lewis AM, Woolliams JA, Williams JL. Muscle-related traits in cattle: the role of the myostatin gene in the South Devon breed. Genet Sel Evol 2002;34:221. https://doi.org/10.1186/1297-9686-34-2-221.

[8] Arthur PF, Makarechian M, Price MA. Incidence of dystocia and perinatal calf mortality resulting from reciprocal crossing of double-muscled and normal cattle. Can Vet J 1988;29(2):163-7.

[9] Abraham MC, Gustafsson H, Ruete A, Brandt YC. Breed influences on in vitro development of abattoir-derived bovine oocytes. Acta Vet Scand 2012;54:36. https:// doi.org/10.1186/1751-0147-54-36.

[10] JLMR Leroy, Opsomer G, De Vliegher S, Vanholder T, Goossens L, Geldhof A, Bols PEJ, de Kruif A, Van Soom A. Comparison of embryo quality in high-yielding dairy cows, in dairy heifers and in beef cows. Theriogenology 2005;64(9):2022-36. https://doi.org/10.1016/j.theriogenology.2005.05.003.

[11] Boujenane I, Boussaq K. Breed effects on semen traits of dairy and beef artificial insemination bulls. Livest Res Rural Dev 2014;26:114http://www.lrrd.org/lrrd26/ 6/Bouje26114.html.
[12] Wydooghe E, Heras S, Dewulf J, Piepers S, Van den Abbeel E, De Sutter P, Vandaele L, Van Soom A. Replacing serum in culture medium with albumin and insulin, transferrin and selenium is the key to successful bovine embryo development in individual culture. Reprod Fertil Dev 2014;26(5):717-24. https://doi.org/10.1071/ RD13043.

[13] Wydooghe E, Vandaele L, Beek J, Favoreel H, Heindryckx B, De Sutter P, Van Soom A. Differential apoptotic staining of mammalian blastocysts based on double immunofluorescent CDX2 and active caspase- 3 staining. Anal Biochem 2011;416(2):228-30. https://doi.org/10.1016/j.ab.2011.05.033.

[14] Cundiff LV, Núñez-Dominguez R, Dickerson GE, Gregory KE, Koch RM. Heterosis for lifetime production in Hereford, Angus, shorthorn, and crossbred cows. J Anim Sci 1992;70(8):2397-410. https://doi.org/10.2527/1992.7082397x.

[15] LaBrie S, Hill L, Grow DR, Margaret A. Inner cell mass quality is more prognostic of blastocyst implantation potential than trophoblast or day 3 embryo quality. Fertil Steril 2008;90:S227. https://doi.org/10.1016/j.fertnstert.2008.07.550.

[16] Cabaraux JF, Dufrasne I, Roux M, Istasse L, Hornick JL. La production de viande bovine à partir de femelles de réforme. INRAE Prod Anim 2005;18(1):37-48. https://doi.org/10.20870/productions-animales.2005.18.1.3508.

[17] Bazzoli I, De Marchi M, Cecchinato A, Berry DP, Bittante G. Factors associated with age at slaughter and carcass weight, price, and value of dairy cull cows. J Dairy Sci 2014;97(2):1082-91. https://doi.org/10.3168/jds.2013-6578.

[18] Snijders SEM, Dillon P, O'Callaghan D, Boland MP. Effect of genetic merit, milk yield, body condition and lactation number on in vitro oocyte development in dairy cows. Theriogenology 2000;53(4):981-9. https://doi.org/10.1016/S0093-691X (00)00244-2.

[19] Vanholder T, Leroy JLMR, Van Soom A, Opsomer G, Maes D, Coryn M, et al. Effect of non-esterified fatty acids on bovine granulosa cell steroidogenesis and proliferation in vitro. Anim Reprod Sci 2005;87(1-2):33-44. https://doi.org/10.1016/ j.anireprosci.2004.09.006. 